\title{
Assessment of the Role of a Second Evaluation of Capsule Endoscopy Recordings to Improve Diagnostic Yield and Patient Management
}

\author{
Gerardo Blanco-Velasco ${ }^{a}$ Rolando Pinho ${ }^{b}$ Omar Michel Solórzano-Pineda ${ }^{a}$

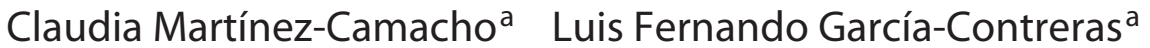 \\ Enrique Murcio-Pérez ${ }^{a}$ Oscar Victor Hernández-Mondragón ${ }^{a}$ \\ aEndoscopy Service, Hospital de Especialidades, Centro Médico Nacional Siglo XXI, Instituto Mexicano del Seguro \\ Social, Ciudad de México, Mexico; ${ }^{b}$ Department of Gastroenterology, Centro Hospitalar Vila Nova de Gaia/Espinho, \\ Vila Nova de Gaia, Portugal
}

Keywords

Capsule endoscopy · Small-bowel bleeding $\cdot$ Crohn's disease

\section{Abstract}

Introduction: The diagnostic yield (DY) of small-bowel capsule endoscopy (SBCE) varies considerably according to its indication. Some strategies have been used to increase DY with varying results. The intention of this study was to identify whether evaluation of the SBCE recordings by a second reviewer can increase DY and change patient management. Methods: One hundred SBCEs with different indications, already read by an endoscopist were read by a second blinded endoscopist. When the results of the 2 readings were different, the images were discussed by the endoscopists; if no consensus was reached, they took the opinion of a third endoscopist into account. All the participating endoscopists had experience in reading SBCEs (i.e., >50 per year). The SBCE findings were divided into positive (vascular lesions, ulcers, and tumors), equivocal (erosions or red spots), and negative. The interobserver agreement and the increase in DY were assessed as well as the percentage of false-negatives (FNs) in the first evaluation. Results: The indications for SBCE were small-bowel bleeding (SBB) in 48 cases, Crohn's disease (CD) in 30, and other causes (iron-deficiency anemia, small-bowel tumors, and diarrhea) in 22. There was substantial interobserver agreement between evaluations ( $\mathrm{k}=0.79)$. The findings in the first evaluation were positive in $60 \%$, equivocal in $20 \%$ and, negative in $20 \%$. In the second evaluation, $66 \%$ were positive, $18 \%$ were equivocal, and $16 \%$ were negative. The increase in DY with the second reading was $6 \%$ ( $p=$ 0.380 ), i.e., $6.3 \%$ for SBB, $4.4 \%$ for CD and $9.2 \%$ for other indications, resulting in a change in management of $4 \%$ of the patients. FNs in the first SBCE reading were found in $4 \%$ of the SBCEs. Discussion: A second evaluation of the SBCE recordings identified significant pathology that the first evaluation had missed, resulting in a nonsignificant $6 \%$ increase in DY and a change in the management of $4 \%$ of the patients.

\footnotetext{
(C) 2021 Sociedade Portuguesa de Gastrenterologia Published by S. Karger AG, Basel
}

Avaliação do papel de uma segunda avaliação dos registos de endoscopia por cápsula para melhorar o rendimento diagnóstico e o manejo dos doentes

Palavras Chave

Endoscopia por cápsula · Hemorragia do intestino delgado · Doença de Crohn karger@karger.com www.karger.com/pjg

Karger $\stackrel{\text { ' }}{5}$

BOPEN ACCESS (c) 2021 Sociedade Portuguesa de Gastrenterologia. Published by S. Karger AG, Basel

This is an Open Access article licensed under the Creative Common Attribution-NonCommercial-4.0 International License (CC BY-NC) (http://www.karger.com/Services/OpenAccessLicense), applicable to the online version of the article only. Usage and distribution for commercial purposes requires written permission.
Correspondence to:

Gerardo Blanco-Velasco, gerardoblancov@ hotmail.com 


\section{Resumo}

Introdução: O rendimento diagnóstico (DY) da enteroscopia por cápsula (SBCE) varia consideravelmente de acordo com as suas indicações. Foram estudadas algumas estratégias para melhorar o DY, com resultados variados. 0 objetivo deste estudo é avaliar se uma segunda leitura de registos de enteroscopia por cápsula por um segundo endoscopista pode melhorar o DY e alterar o manejo dos doentes. Métodos: 100 SBCE realizadas por indicações variadas, previamente avaliadas por um endoscopista, foram reavaliadas por um segundo endoscopista cego para a primeira leitura. Na presença de resultados discordantes nas 2 leituras, as imagens foram discutidas pelos 2 endoscopistas, e por um terceiro na ausência de consenso entre os 2 primeiros. Todos os endoscopistas são experientes na leitura de SBCE (>50 SBCE/ano). Os achados foram categorizados em positivos (lesões vasculares, úlceras e tumores), equívocos (erosões e pontos vermelhos) e negativos. Foi avaliada a concordância inter-observador e o aumento do DY, bem como a percentagem de falsos negativos da primeira avaliação. Resultados: As indicações para SBCE foram hemorragia do intestino delgado (SBB) em 48 casos, doença de Crohn (CD) em 30 e outras causas (anemia por défice de ferro, pesquisa de tumores do intestino delgado e diarreia) em 22. A concordância inter-observador foi substancial ( $\mathrm{k}=0.79)$. Os achados da primeira avaliação foram positivos em $60 \%$, equívocos em $20 \%$ e negativos em $20 \%$, enquanto na segunda avaliação foram positivos em $66 \%$, equívocos em $18 \%$ e negativos em $16 \%$. O aumento de DY foi de $6 \%$ com a segunda leitura $(p=0.38)$, sendo $6.3 \%$ para SBB, $4.4 \%$ para CD e $9.2 \%$ para outras indicações, resultando numa alteração no manejo de $4 \%$ dos doentes. Foram identificados falsos negativos na primeira avaliação em $4 \%$ das SBCE. Conclusão: A segunda avaliação dos registos de SBCE identificou patologia significativa previamente não identificada, resultando num aumento não significativo de $6 \%$ do DY e numa alteração no manejo de $4 \%$ dos doentes.

( 2021 Sociedade Portuguesa de Gastrenterologia Publicado por S. Karger AG, Basel

\section{Introduction}

The diagnostic yield (DY) of small-bowel capsule endoscopy (SBCE) may vary depending on the indication. In obscure gastrointestinal bleeding (OGIB), the DY could be as high as $93 \%$ in ongoing overt bleeding and as low as $12.9 \%$ in previous overt bleeding [1]. Concerning other indications, the DY of SBCE is around $47 \%$ in irondeficiency anemia (IDA) [2], 52\% for Crohn's disease
(CD) [3], and 42.9\% for diarrhea [4]. Some strategies, e.g., the use of simethicone and prokinetics, have been proposed to increase the diagnostic rate of capsule endoscopy with varying results [5].

There is limited evidence of the usefulness of a second evaluation of SBCE recordings. A study showed that a "back-to-back" evaluation increased the DY of the first from 37.5 to $62.5 \%$ [6]. "Back-to-back" in SBCE recordings has been used in other studies to assess DY but using different SBCE platforms [7, 8].

The little evidence that exists seems to show that the second evaluation can increase SBCE performance. The aim of this study is to assess whether a second evaluation of SBCE recordings by another reviewer can increase the DY and improve patient management.

\section{Materials and Methods}

\section{Study Design}

SBCE (Pillcam SB3; Given Imaging Ltd., Yoqneam, Israel) recordings with different indications, already read by a first endoscopist, were reread by a second blinded endoscopist. When the findings from the 2 revisions were different, the images were discussed by the endoscopists; if they did not reach consensus, they took the opinion of a third endoscopist into account. The first evaluation was considered as the finding of the first endoscopist only, while the second evaluation was considered as the finding of the second endoscopist plus the agreement reached in the case of different findings. All the participating endoscopists had experience in reading SBCE (i.e., >50 CE per year).

\section{SBCE Selection}

A total of 100 SBCEs with various indications, performed from August 2019 to October 2020, were included. All patients were prepared with $2 \mathrm{~L}$ of polyethylene glycol and an 8 -h fast before the ingestion of the endoscopy capsule. Real-time review was used in all patients. In the event that the capsule did not pass into the duodenum after $60 \mathrm{~min}$, metoclopramide $(10 \mathrm{mg}$ i.v.) was administered. If no progress was made after $90 \mathrm{~min}$, the capsule was placed endoscopically in the duodenum. The belt and the data recorder were removed $12 \mathrm{~h}$ after they were placed.

\section{Outcome Measures}

The SBCE findings were classified by using capsule endoscopy structured terminology (CEST) [9] and divided in 3 groups: (1) positive, if significant lesions such as vascular lesions, ulcers, and tumors were found; (2) equivocal if nonspecific lesions such as erosions or red spots were found; and (3) negative, in the presence of irrelevant lesions or absence of findings. Only positive findings were considered as contributing to a positive DY. As per protocol, false-negative (FN) findings could only present in the first evaluation; they were defined as findings (either positive or equivocal) in the second evaluation not identified in the first evaluation. The recordings were read at a maximum speed of 10 frames per second in a single view, in line with the European Society of Gastrointestinal Endoscopy (ESGE) Quality Improvement Initiative [10]. 
Table 1. Agreement between endoscopists by indications

\begin{tabular}{lcccc}
\hline & SBB & CD & Other causes1 & Total \\
\hline $\begin{array}{l}\text { Number of cases } \\
\begin{array}{c}\text { Agreement between } \\
\text { endoscopists }\end{array}\end{array}$ & 48 & 30 & 22 & 100 \\
\hline \multicolumn{1}{c}{ endo.79 } & $\kappa=0.78$ & $\kappa=0.74$ & $\kappa=0.79$ \\
\hline
\end{tabular}

SBB, small-bowel bleeding; CD, Crohn's disease.

${ }^{1}$ Iron-deficiency anemia, small-bowel tumors, and diarrhea.

Table 3. Changes in positive findings after the second evaluation

\begin{tabular}{llll}
\hline Case No. & Indication & First evaluation & Second evaluation \\
\hline 1 & IDA & erosions & ulcer \\
2 & SBB & erosions + red spots & ulcer \\
3 & SBB & normal & angioectasia \\
4 & CD & normal & ulcer \\
5 & SBB & erosions & angioectasia \\
6 & IDA & normal & GIST \\
\hline
\end{tabular}

SBB, small-bowel bleeding; CD, Crohn's disease; IDA, irondeficiency anemia; GIST, gastrointestinal stromal tumor.

\section{Sample Calculation}

To calculate the sample size, the formula for the difference of 2 proportions was used. The calculation was based on the results of Min et al. [6] in which the DY of the first SBCE evaluation was $37.5 \%$ and the DY of the "back-to-back" SBCE was $62.5 \%$. Epi Info software v3, considering a confidence interval (CI) of 95\% and a statistical power of $80 \%$, was used for sample size calculation. The estimated sample size was 70 patients per evaluation; however, to increase power, $100 \mathrm{SBCE}$ recordings were included.

\section{Statistical Analysis}

Qualitative variables were calculated as frequencies and percentages. To study the relation between qualitative variables, the $\chi^{2}$ test was used. The interobserver agreement was assessed by using Cohen's kappa $(\kappa)$ coefficient. The $\kappa$ index was divided as slight agreement when the value was $<0.20$, fair at $0.21-0.40$, moderate at $0.41-0.60$, substantial at $0.61-0.80$, and almost perfect when $>0.81 . p<0.05$ was considered statistically significant. SPSS v22 (IBM, Chicago IL, USA) was used for statistical analysis.

\section{Results}

The indications for SBCE were small-bowel bleeding (SBB) in 48 cases, suspected or confirmed CD in 30, and other causes (IDA, small-bowel tumors, and diarrhea) in 22. There was good interobserver agreement between the 2 evaluations $(\kappa=0.79$; Table 1$)$.
Table 2. Findings in the first and second evaluations

\begin{tabular}{|c|c|c|c|c|}
\hline & Positive & Equivocal & Negative & $\begin{array}{l}p \\
\text { value }\end{array}$ \\
\hline First evaluation & $60(60)$ & $20(20)$ & $20(20)$ & \multirow{8}{*}{0.66} \\
\hline SBB & $32(66.7)$ & $9(18.7)$ & 7 (14.6) & \\
\hline $\mathrm{CD}$ & $20(66.7)$ & $7(23.3)$ & $3(10)$ & \\
\hline Other causes ${ }^{1}$ & $8(36.4)$ & $4(18.2)$ & $10(45.4)$ & \\
\hline Second evaluation & $66(66)$ & $18(18)$ & $16(16)$ & \\
\hline SBB & $35(73)$ & $7(14.5)$ & $6(12.5)$ & \\
\hline CD & $21(70)$ & 8 (26.7) & $1(3.3)$ & \\
\hline Other causes ${ }^{1}$ & $10(45.5)$ & $3(13.6)$ & $9(40.9)$ & \\
\hline
\end{tabular}

Values express $n$ (\%). SBB, small-bowel bleeding; CD, Crohn's disease.

${ }^{1}$ Iron-deficiency anemia, small-bowel tumors, and diarrhea.

In the first evaluation, findings were considered positive in $60 \%$, equivocal in $20 \%$, and negative in $20 \%$ of the cases. In the second evaluation, they were positive in $66 \%$, equivocal in $18 \%$, and negative in $16 \%$. (Table 2 ). The changes in the type of findings from the second evaluation are detailed in Table 3. On 2 occasions, the intervention of a third endoscopist was required for consensus. These involved a gastrointestinal stromal tumor initially reported as normal and an ulcer diagnosed as "erosions and red spots" in the first evaluation.

The DY was $60 \%$ for the first evaluation and $66 \%$ after the second evaluation, resulting in a $6 \%$ increase $(p=$ 0.38 ). The increased DY according to the indications was $6.3 \%$ for SBB, $4.4 \%$ for $\mathrm{CD}$, and $9.2 \%$ for others. After the second evaluation, patient management was changed in 4 of these 6 patients; 1 of these 4 underwent surgery, 2 underwent therapeutic enteroscopy, and 1 had their medical therapy changed.

FNs were found in $4 \%$ of the SBCEs (cases 3, 4, and 6 in Table 3 and 1 case that went from normal to equivocal) after the second evaluation. The FN rate according to the indication was $2 \%$ for SBB, $6.7 \%$ for CD, and $4.5 \%$ for other indications.

\section{Discussion}

The interobserver agreement of SBCE findings has been reported as ranging from moderate to substantial $(\kappa=0.48-0.71)$ [11-14]. It also depends on the indications and the experience of the endoscopist. In cases of $\mathrm{SBB}$, it can vary from $\kappa=0.71$ for evaluations by senior endoscopists to $\kappa=0.56$ for those made by junior endoscopists [13]. In CD, the interobserver agreement has been 
reported as substantial $(\kappa=0.68)$ [15]. In our study, the interobserver agreement was substantial and did not vary according to the different indications.

The ESGE Quality Improvement Initiative mentions that currently available data do not support a single optimal DY per indication. For mixed indications, the DY varies between 27 and $77.3 \%$ and, for suspected gastrointestinal bleeding, between 31 and 68\% [10]. In this study, the DY in the first evaluation was already high at $60 \%$, ranging from $66.7 \%$ for SBB and CD to $36.4 \%$ for other indications.

There have been several attempts to improve the DY of SBCE. The use of small-bowel preparation, antifoaming agents, or prokinetics has been proposed. Recent systematic reviews and meta-analyses to evaluate whether bowel preparation before SBCE improves the DY concluded that there are no clear advantages [16-18]. It has been suggested that a "second-look" with another SBCE can increase the DY. Svarta et al. [19] found positive findings in 55\% of repeated SBCEs that resulted in a change in management in $39 \%$ of the patients. In our study, a second evaluation of the same capsule increased the DY by $6 \%$; however, it was time-consuming and no statistically significant difference was found.

Van de Bruaene et al. [20] identified FNs in $9 \%$ of the SBCEs. They defined FNs as bleeding sources located in the small bowel but not diagnosed during the initial SBCE. In our study, FNs were found in $4 \%$, but our definition of FN was different.

The final diagnosis was changed in 6 cases. Three of these were initially diagnosed as erosions and red spots; in the other 3, the SBCE results were reported as normal. Although not reaching statistical significance, these findings are nonetheless of obvious relevance. In $4 \%$ of the patients, a change in management resulted from the reevaluation. In 1 case, a gastrointestinal stromal tumor not diagnosed at the first evaluation and requiring surgical intervention was found. Another 2 patients required therapeutic endoscopy using argon plasma coagulation to treat angioectasia. One patient diagnosed as having CD had a change in medical therapy after ulcers were found at the second evaluation. The diagnosis remained nonsteroidal anti-inflammatory drug (NSAID)-induced enteropathy in 2 patients.

The lack of statistical significance is likely due to the high DY present in the first evaluation. It is at the upper end of previously reported data and similar to the DY obtained after the "back-to-back" approach in the study by Min et al. [6] used to calculate the sample size. This high DY probably reflects improved patient selection and improvements in SBCE technology in recent series. Further studies evaluating gains in DY after interventions, like second evaluations, the use of bowel preparations, or new protocols, should take into account the higher initial DY and marginal increases in DY.

\section{Conclusion}

Relevant findings missed in a first evaluation are often identified at a second evaluation, resulting in relevant changes in patient management. Due to the time-consuming nature of SBCE reading, a second evaluation could be selectively offered to negative SBCE patients with suspected pathology. Further studies evaluating interventions to improve the DY of SBCE should take into account the higher initial DY than was previously reported, and, consequently, more modest gains in DY.

\section{Acknowledgment}

We did not have assistance with this article.

\section{Statement of Ethics}

This study is in line with the regulations of the Mexican General Health Law regarding health research and the Declaration of Helsinki as well as the rules and institutional instructions on scientific research. SBCE is proven to be safe, so this was classified as a withoutrisk study. The study was performed under authorization of the hospital's Ethics and Research Committee (R-2020-3601-161).

\section{Conflict of Interest Statement}

G.B.-V. has participated in speaking activities for Medtronic and Jinshan Science and Technology Co. The other authors have no conflicts of interest to declare.

\section{Funding Sources}

We did not receive financial assistance for this article.

\section{Author Contributions}

G.B.-V. made substantial contributions to the conception, acquisition, analysis, and interpretation of data for the work. R.P. made substantial contributions to the conception, analysis, and interpretation of data for the work. O.M.S.-P., C.M.-C., and L.F.G.-C. made substantial contributions to the conception and acquisition of data for the work. E.M.-P. agreed to be accountable for all aspects of the work in ensuring that questions related to the accuracy or integrity of any part of the work are appropriately investigated and resolved. O.V.H.-M. gave final approval of the version to be published. 


\section{References}

1 Pennazio M, Santucci R, Rondonotti E, Abbiati C, Beccari G, Rossini FP, et al. Outcome of patients with obscure gastrointestinal bleeding after capsule endoscopy: report of 100 consecutive cases. Gastroenterology. 2004 Mar;126(3):643-53.

2 Koulaouzidis A, Rondonotti E, Giannakou A, Plevris JN. Diagnostic yield of small-bowel capsule endoscopy in patients with iron-deficiency anemia: a systematic review. Gastrointest Endosc. 2012 Nov;76(5):983-92.

3 Mehdizadeh S, Chen GC, Barkodar L, Enayati PJ, Pirouz S, Yadegari M, et al. Capsule endoscopy in patients with Crohn's disease: diagnostic yield and safety. Gastrointest Endosc. 2010 Jan;71(1):121-7.

4 Song HJ, Moon JS, Jeon SR, Kim JO, Kim J, Cheung DY, et al.; Korean Gut Image Study Group. Diagnostic Yield and Clinical Impact of Video Capsule Endoscopy in Patients with Chronic Diarrhea: A Korean Multicenter CAPENTRY Study. Gut Liver. 2017 Mar;11(2):253-60.

5 Villa F, Signorelli C, Rondonotti E, de Franchis R. Preparations and prokinetics. Gastrointest Endosc Clin N Am.2006 Apr;16(2):21120.

6 Min BH, Chang DK, Kim BJ, Lee IS, Choi MG. Does Back-To-Back Capsule Endoscopy Increase the Diagnostic Yield over a Single Examination in Patients with Obscure Gastrointestinal Bleeding? Gut Liver. 2010 Mar;4(1):54-9.

7 Kim HM, Kim YJ, Kim HJ, Park S, Park JY, Shin SK, et al. A Pilot Study of Sequential Capsule Endoscopy Using MiroCam and PillCam SB Devices with Different Transmission Technologies. Gut Liver. 2010 Jun;4(2):192200
8 Dolak W, Kulnigg-Dabsch S, Evstatiev R, Gasche C, Trauner M, Püspök A. A randomized head-to-head study of small-bowel imaging comparing MiroCam and EndoCapsule. Endoscopy. 2012 Nov;44(11):1012-20.

9 Korman LY, Delvaux M, Gay G, Hagenmuller F, Keuchel M, Friedman S, et al. Capsule endoscopy structured terminology (CEST): proposal of a standardized and structured terminology for reporting capsule endoscopy procedures. Endoscopy. 2005 Oct;37(10):951-9.

10 Spada C, McNamara D, Despott EJ, Adler S, Cash BD, Fernández-Urién I, et al. Performance measures for small-bowel endoscopy: a European Society of Gastrointestinal Endoscopy (ESGE) Quality Improvement Initiative. Endoscopy. 2019 Jun;51(6):574-98.

11 Pezzoli A, Cannizzaro R, Pennazio M, Rondonotti E, Zancanella L, Fusetti N, et al. Interobserver agreement in describing video capsule endoscopy findings: a multicentre prospective study. Dig Liver Dis. 2011 Feb;43(2):126-31.

12 Lai LH, Wong GL, Chow DK, Lau JY, Sung JJ, Leung WK. Inter-observer variations on interpretation of capsule endoscopies. Eur J Gastroenterol Hepatol. 2006 Mar;18(3):2836.

13 Jang BI, Lee SH, Moon JS, Cheung DY, Lee IS, Kim JO, et al. Inter-observer agreement on the interpretation of capsule endoscopy findings based on capsule endoscopy structured terminology: a multicenter study by the Korean Gut Image Study Group. Scand J Gastroenterol. 2010 Mar;45(3):370-4.

14 De Leusse A, Landi B, Edery J, Burtin P, Lecomte T, Seksik P, et al. Video capsule endoscopy for investigation of obscure gastrointestinal bleeding: feasibility, results, and interobserver agreement. Endoscopy. 2005 Jul;37(7):617-21.
15 Jensen MD, Nathan T, Kjeldsen J. Inter-observer agreement for detection of small bowel Crohn's disease with capsule endoscopy. Scand J Gastroenterol. 2010 Aug;45(78):878-84.

16 Kotwal VS, Attar BM, Gupta S, Agarwal R. Should bowel preparation, antifoaming agents, or prokinetics be used before video capsule endoscopy? A systematic review and meta-analysis. Eur J Gastroenterol Hepatol. 2014 Feb;26(2):137-45.

17 Gkolfakis P, Tziatzios G, Dimitriadis GD, Triantafyllou K. Meta-analysis of randomized controlled trials challenging the usefulness of purgative preparation before small-bowel video capsule endoscopy. Endoscopy. 2018 Jul;50(7):671-83.

18 Yung DE, Rondonotti E, Sykes C, Pennazio M, Plevris JN, Koulaouzidis A. Systematic review and meta-analysis: is bowel preparation still necessary in small bowel capsule endoscopy? Expert Rev Gastroenterol Hepatol. 2017 Oct;11(10):979-93.

19 Svarta S, Segal B, Law J, Sandhar A, Kwok R, Jacques A, et al. Diagnostic yield of repeat capsule endoscopy and the effect on subsequent patient management. Can J Gastroenterol. 2010 Jul;24(7):441-4.

20 Van de Bruaene C, Hindryckx P, Snauwaert C, Dooremont D, Vanduyfhuys B, Vandenabeele $\mathrm{L}$, et al. The predictive value of negative capsule endoscopy for the indication of Obscure Gastrointestinal Bleeding: no reassurance in the long term. Acta Gastroenterol Belg. 2016 Sep-Dec;79(4):405-13. 